\title{
DOSSIÊ
}

Niura Legramante Ribeiro

\section{A fotografia contemporânea e seus compartilhamentos pictóricos: antinomias e convergências}

\section{Resumo}

Os compartilhamentos entre fotografia e pintura na arte contemporânea podem apresentar ao menos dois regimes fundacionais para os processos de criação de obras: propor antinomias como descontinuidades entre os conteúdos da representação de imagem e as narrativas verbais a ela associadas, procurando colocá-los em tensão, ou, por outro lado, buscar convergências entre texto e imagem. Pensar de que forma o universo da tradição pictórica serve de arcabouço compositivo para as práticas fotográficas é a proposição para este artigo, por meio de estudos de caso em determinadas obras de Dirnei Prates e Felipe Cama.

\section{Palavras-chave}

Fotografia. Pintura. Compartilhamentos. Antinomias. Convergências. 
1. PONGE apud PICAUDÉ; ARBAÏZAR, 2004, p. 107.

2. PICAUDÉ, Valérie. Clasificar la fotografía, con Perec, Aristóteles, Searle $Y$ algunos otros. In: PICAUDÉ; ARBAÏZAR, 2004, p. 23.

3. DURAND, 2012, p.116.
Os repertórios compositivos de elementos temáticos e de disposições espaciais da fotografia foram, como se sabe, desde seu surgimento, tomados emprestados da tradição da pintura nos seus diversos gêneros, paisagens, nus e naturezas-mortas, entre outros, como muito bem analisaram Aaron Scharf e Van Deren Coke em suas publicações.

Pode parecer estranho, mas não é nada paradoxal pensar que a questão dos gêneros tradicionais da História da Arte esteja sendo compartilhada por determinados artistas contemporâneos, já que muitos deles estão interessados em trabalhar pelo viés das mestiçagens de meios, materiais, períodos, disciplinas, categorias de gênero e temas, provocando revisitações em relação ao passado da História da Arte.

Para Francis Ponge, o gênero, especialmente na pintura, é aquilo em que um pintor se especializou, uma condição para a maestria na pintura, indissociável para o artista. ${ }^{1}$ No livro La confusión de los géneros en fotografia, Valérie Picaudé afirma que o gênero, entre outras concepções, trata de "um tipo de imagens que possuem qualidades comuns e uma categoria mental segundo a qual se regula a percepção das imagens". ${ }^{2}$ Portanto, em uma das concepções de gênero, está implícita a ideia de classificação por tipologias de representação.

Devido à explosão quantitativa de imagens fotográficas, o que na atualidade parece primordial para determinados artistas é a administração do manejo das imagens. Como afirma Régis Durand, o mundo contemporâneo de imagens "acumula, arquiva e pratica a reciclagem permanente". ${ }^{3}$ Entre os modos operatórios empregados nos trabalhos de artistas contemporâneos, estão o uso de imagens de imagens, a citação, as reciclagens, o desvio de finalidades, a descontextualização, as misturas de referências, os jogos com a história das imagens e os empréstimos visuais entre diferentes disciplinas.

Para lançar mão destas possibilidades, alguns artistas contam com os repertórios oferecidos pela internet, pelas tecnologias multimídia, procurando por imagens no Google Street View - que, como se sabe, permite localizar e visualizar lugares distantes, muitas vezes inacessíveis -, em sites de relacionamento, em endereços eletrônicos que reproduzem obras da História da Arte e nas publicações em jornais. Assim, todas estas células de comunicação têm viabilizado as construções narrativas de determinadas práticas fotográficas 
na contemporaneidade. A manipulação de imagens dessas fontes visando a produzir ressignificações ou mesmo atualizações constituem atos fundacionais de processos artísticos. São estas as estratégias a que recorrem artistas como Dirnei Prates e Felipe Cama.

\section{I - AS RESSIGNIFICAÇÕES COMO ARTE DE IMAGENS PRIVADAS E DE INFORMAÇÃO}

Não é raro encontrar na arte contemporânea a relação entre fotografias de imprensa que são utilizadas como arcabouço para pinturas, como fizeram o pintor alemão Gerhardt Richter, o pintor belga Luc Tuymans e a Pop Art, entre outros. No sentido inverso, isso também ocorre - fotografias de imprensa são reativadas por trabalhos na própria fotografia e guardam referenciais pictóricos.

Recorrer a "imagens que não são de arte" é uma estratégia detectada pelo pesquisador americano James Elkins ${ }^{4}$ ao analisar como a História da Arte explora imagens de outras disciplinas, adotando empréstimos de convenções formais e expressivas para composições em arte. Assim, a História da Arte passou a interessar-se por imagens "não arte" que são utilizadas para "iluminar a história da visualidade". O que faz a diferença no significado das imagens são as utilizações e as estratégias de manipulação.

Imagens de imprensa já ganharam espaços nos museus. Em busca de estatuto artístico, fotojornalistas apresentaram imagens de imprensa no espaço museal, com estratégias que consistiam em retirar a legenda para descontextualizar o fato jornalístico, apresentar as imagens em escalas generosas, realizar novos enquadramentos e tornar a imagem única, como lembra Michel Poivert ${ }^{5}$ ao analisar os procedimentos expositivos institucionais nas relações entre imagens de imprensa e práticas artísticas.

Nas produções fotográficas de Dirnei Prates, imagens e títulos são inseparáveis, porque é da associação entre esses dois elementos que os trabalhos se formam e adquirem suas novas propriedades estéticas. 0 que suas diversas séries fotográficas têm em comum são as relações de diálogos que estabelecem com o universo da pintura.

A relação de suas fotografias com paisagens está nas séries Paisagens Populares (2011-2012) ${ }^{6}$ e Verdes Complementares (2012-2013), originadas de fotografias publicadas em jornais. A reativação de fotografias de imprensa ${ }^{7}$ é o método empregado por Dirnei Prates em sua prática artística, cujas imagens, depois de recontextualizadas, transformam a finalidade informativa original. Não interessa mais o fato jornalístico, mas as possibilidades expressivas de dar a ver o que as imagens contêm em planos anteriormente não valorizados. A sua pesquisa estética explora uma proposição da lógica do dispositivo fotográfico
4. ELKINS, 2011, p. 10-11.

5. POIVERT, Michel. De l'Image imprimée à l'image exposée: La photographie de reportage et le "mythe de L'exposition". In: MOREL, 2008, p. $87-100$

6. Duas obras dessa série pertencem ao acervo do Centro Cultural São Paulo, São Paulo, por meio do Prêmio Aquisição, em 2012, a partir de uma exposição lá realizada entre outubro de 2012 e janeiro de 2013; outra obra pertence ao acervo do Museu de Arte Contemporânea do Rio Grande do Sul.

7. Não é de hoje a utilização de imagens de fotojornalismo como experiências plásticas. Além das colagens dadaístas, entre outras, um exemplo na arte contemporânea é a exposição Covering the Real, Art and Press Picture, from Warhol to Tillmans, em 2005, no Kunstmuseum de Bâle, concebida por Hartwig Fischer. Esta exposição explorava a relação entre a arte contemporânea e a imagem de imprensa depois dos anos de 1960 até 2005 e incluía pintura, fotografia e instalações de vídeo, dispostos em nove salas. Associava ainda projeções de fotografias de imprensa de agência em tempo real. Participaram obras de 25 artistas internacionais, dentre os quais, Andy Warhol, Malcolm Morley, Gerhardt Richter, Richard Hamilton, Sigmar Polke e Arnulf Rainer. Para Gäelle Morel, a exposição "reconhecia a importância dentro da história da arte, da reapropriação de iconografia de imprensa pelos artistas". Ainda segundo Morel, os "artistas interrogam as regras econômicas, estéticas e morais" das imagens do fotojornalismo e, desta forma, transformam o caráter funcional da imagem de imprensa em proveito da experiência plástica. Muitas das imagens de imprensa determinaram uma parte significativa dos projetos artísticos. MOREL, 2008, p. 139-140. 


\section{Dossiê}

Dirnei Prates, Polícia inspecionará poços em busca de jovem sumida (Série Verdes Complementares), 2012-2013, fotografia, $70 \times 100 \mathrm{~cm}$, coleção do artista. Fonte: arquivo do artista.
8. Esta série recebeu menção honrosa no Prêmio Brasil de Fotografia (2013); a série também foi exposta no $64^{\circ}$ Salão de Abril, em Fortaleza (2013), no $32^{\circ}$ Arte Pará, em Belém do Pará (2013) e no $19^{\circ}$ Salão Unama de Pequenos Formatos, Amazonas (2013), além de exposição no Palácio das Artes, Galeria Arlinda Corrêa Lima, em Belo Horizonte (2013), e na Bienal do Mercosul (2015).

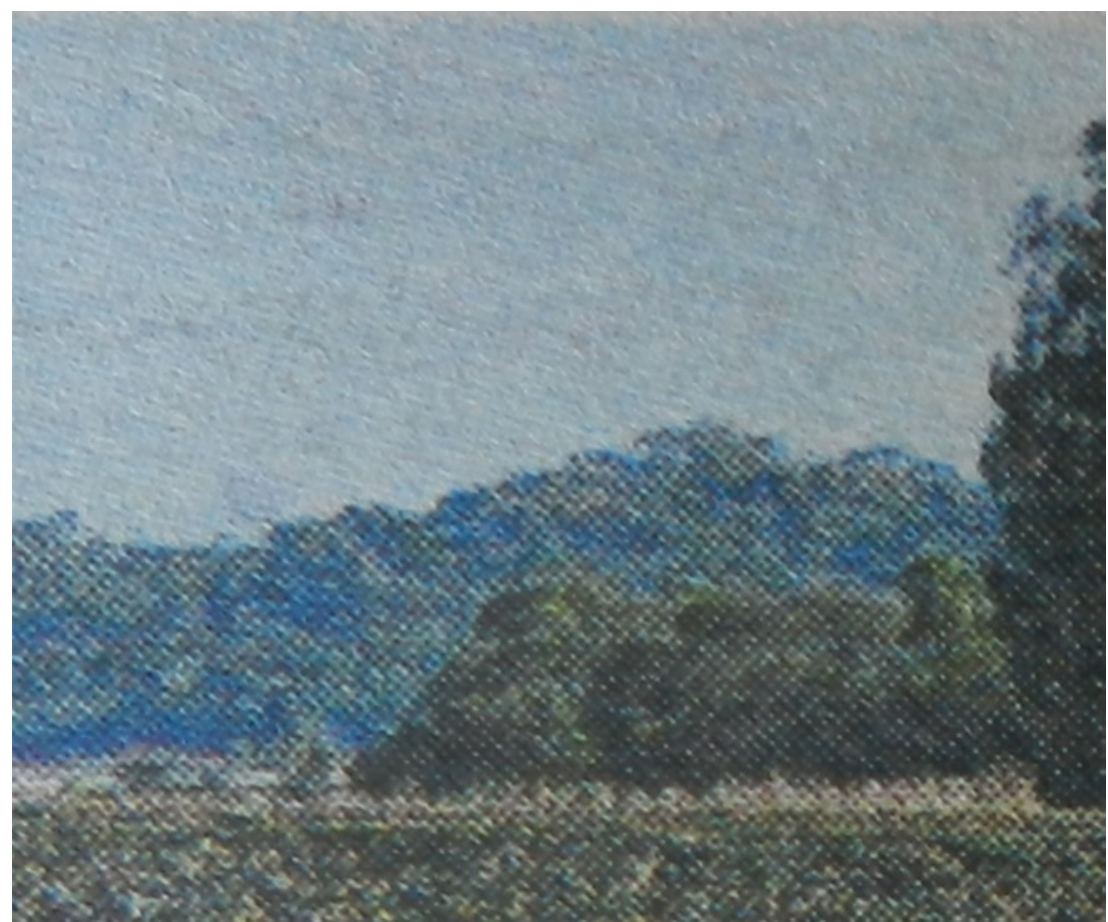

de captação da imagem: uma fotografia que comenta a própria fotografia. 0 artista procede por meio de reenquadramentos, ampliando o plano de fundo das imagens originais. Tal ampliação expande o fundo da imagem até o ponto de desconfigurar a composição da imagem de origem e, como consequência, evidencia os pontos granulados da matéria fotográfica. Ao implodir os referenciais realistas, o artista danifica a capacidade descritiva da imagem fotográfica e, portanto, de documento do fato. 0 que lhe interessa não é conservar o estatuto de documento enquanto imagem, mas reinterpretar uma imagem do real.

A série Verdes Complementares (2012-2013) ${ }^{8}$ produz uma descontinuidade dos conteúdos de representação no que se refere a imagem e título. Para os trabalhos dessa série, o artista busca imagens documentais de notícias de impacto publicadas nos jornais que tratam de crimes, acidentes de trânsito e mortes, entre outros tipos de violência. 0 interesse na imagem concentra-se na ampliação dos planos de fundo, em que somente a paisagem, desprovida de figura humana, acaba sendo reapresentada, excluindo, portanto, o primeiro plano, que registra o fato documental da violência. Ao descontextualizar o fato em si, o artista retira o caráter documental da imagem.

É na garimpagem de imagens em jornais que o artista escolhe aquelas com possibilidades de melhor adequação à realização de uma macrofotografia e com noções estéticas de paisagens que possam desprender-se da imagem 


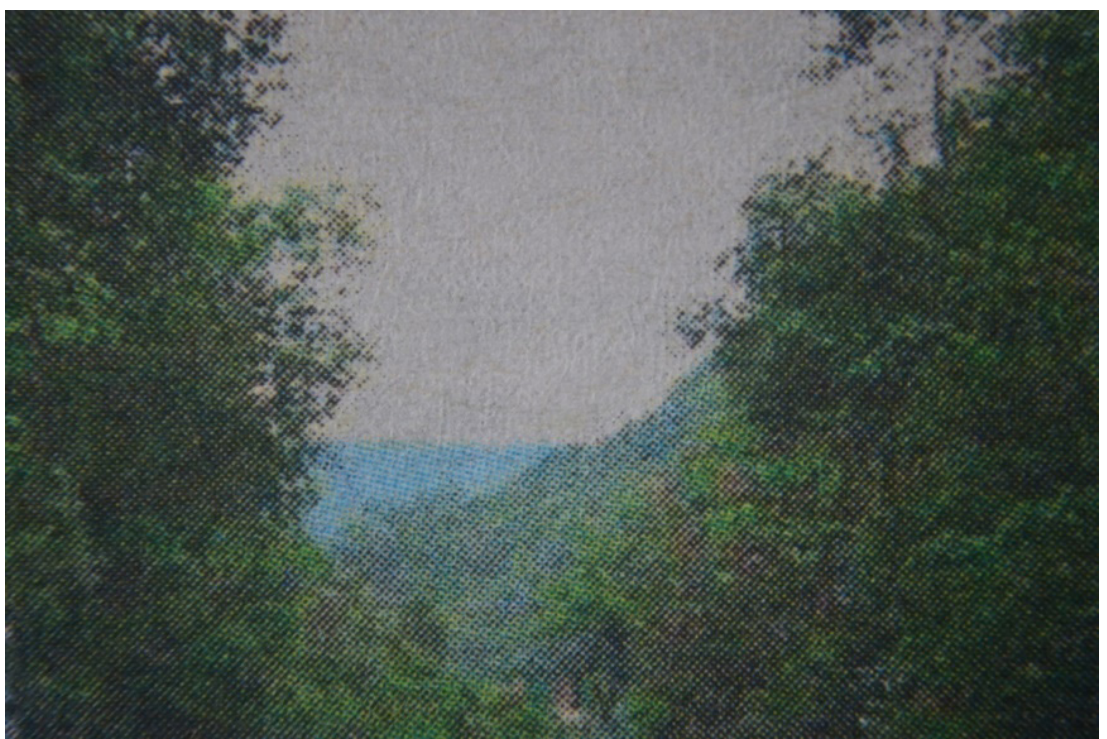

original. A concepção de André Malraux de que a fotografia é mestre em criar "artes fictícias", referindo-se à escala das imagens em relação ao real, foi levada a cabo nas fotografias de Dirnei Prates. A imagem figurativa original acaba por tornar-se imperceptível devido ao pequeno detalhe que é ampliado para dimensões de aproximadamente 2 metros e, às vezes, 4,60 m, se comparadas às das imagens de pequeno formato do jornal. Tal escala resulta em um tableau photographique, para usar a expressão cunhada por Jean-François Chevrier, reenviando, portanto, a uma tradição de escala mais pictural que fotográfica. Como consequência desta amplitude, a imagem acaba tendo a superfície com aparência granulada pela presença da retícula; isto revoga a perspectiva e evidencia o desfocamento, pois a mínima inclinação do papel no momento de refotografar já provoca esse desfoque. 0 grão faz perder o caráter de realidade que acentuaria o caráter mecânico de imagem. Em relação à valorização da evidência da retícula, pode-se lembrar de obras como Déjeneur sur l'herbe (1964), de Alain Jacquet, ou de diversos trabalhos de Sigmar Polke, dentre outros artistas.

O título da série é indicativo de uma referência pictórica pela escolha de cores complementares. 0 artista não adota nenhum procedimento de pós-produção em relação às cores, mas declara que opta por imagens que já apresentam predominância de cores verde (paisagem) e vermelha (elementos em primeiro plano), ${ }^{9}$ apesar de o vermelho deste plano desaparecer ao serem reenquadrados os fundos das imagens. Além disso, as fotografias são dotadas de fortes cromatismos visíveis, sobretudo, quando ampliadas. Mesmo desfocadas, ainda é possível reconhecer elementos figurativos da natureza, quase sempre sem a presença humana, tanto em Paisagens Populares quanto em Verdes
Figura 2. Dirnei Prates, Dois caminhões e um Vectra se envolveram em batida (Série Verdes Complementares), 20122013 , fotografia, $70 \times 120 \mathrm{~cm}$, coleção do artista. Fonte: arquivo do artista.
9. Entrevista à autora em 15 de janeiro de 2016. 
10. Ibidem.

11. DURAND, 2012, p. 156.

12. Ibidem, p. 136.

13. Ibidem, p. 158.

14. Duas obras dessa série pertencem ao acervo do Museu de Arte do Rio Grande do Sul: Child with a toy grenade in central park - Diane Arbus (2011) e Street execution of a vietcong prisoner - Eddie Adams (2011). Em 2012, a exposição na Galeria Virgílio Calegari recebeu $01^{\circ}$ Prêmio IEAVI, Porto Alegre.
Complementares. Nessas imagens, muito embora não apresentem uma fatura clássica e a perspectiva possa ficar comprometida, o artista conserva, na maioria das vezes, a "linha do horizonte, a ideia de céu e terra ou que seja a presença de um morro", no dizer de Prates, para que "possa referenciar o gênero da paisagem na tradição pictórica". ${ }^{10}$

A obra de Dirnei não cessa de interrogar o instante do encontro entre a imagem e o texto, quebrando a expectativa do espectador ao ler os títulos das fotografias. A associação entre texto-imagem "representa uma fonte inesgotável de produção de dispositivos e de sentidos",11 afirma Régis Durand. Se as paisagens reativadas da imprensa e ressignificadas por Prates podem evocar lugares bucólicos, não é o que acontece quando nos deparamos com o título das fotografias: Após 23 h corpo é localizado em arroio; Caminhões e um Vectra se envolvem numa batida na BR 116; Ao tentar ingressar na rodovia, Parati foi atingida por um Clio; Duas mulheres morrem na colisão de um Uno (foto) e um Civic, em T; Elba foi achado uma hora após o corpo de L; Pai e filho morrem em acidente em V. F.; Polícia inspecionará poços em busca de jovem sumida. A observação da frequência deste tipo de notícias nos jornais leva o artista a desenvolver essas séries. Sua escolha recai em imagens cujos títulos exploram violências, justamente para reforçar a incompatibilidade com a imagem representada, em uma associação que reforça a ideia de ficção. É preciso considerar que "o que vemos na atualidade são obras que reivindicam uma heterogeneidade ou uma descontinuidade profunda em sua mesma materialidade, porém, também em seus conteúdos de representação", como bem observou Régis Durand. ${ }^{12}$ Este autor francês alerta ainda para "o perigo inerente ao poder da imagem de provocar no espectador um conflito e algumas associações incontroláveis"13 E é justamente essa provocação de colocar imagem e texto em tensão que essa série parece produzir na percepção do trabalho. Assim como para René Magritte em Le clef des songes (1930), aqui há, portanto, um paradoxo entre a representação da imagem e o significado do texto, entre o que o espectador vê e lê.

A reativação de imagens por meio de reenquadramentos também se faz presente em Zona de Neutralidade (2011), ${ }^{14}$ em que Prates reapresenta partes de fotografias históricas do século XX publicadas em livros sobre fotografias de autores como: Diane Arbus, Eddie Adams, Ian Berry, Josef Koudelka, Max Alpert, Nick Ut, Sam Shere e Thurston Hopkins. Desta vez, inclui figuras humanas, mesmo que irreconhecíveis devido ao desfoque causado pela ampliação. Por tratar-se de fotografias muito conhecidas, podem ser vistas como um teste à percepção do espectador, na tentativa de identificar a qual fotografia se refere o fragmento ampliado. Este é o caso da fotografia de Diane Arbus, Child with a toy grenade in central park (1962), em que Dirnei reapresenta as figuras 
do fundo que se encontravam no parque, em fotografia de mesmo título e em preto e branco, datada de 2011. Na fotografia de Dirnei, as pessoas aparecem como manchas, e, na verdade, nem se pode supor que se trata de pessoas. Da mesma forma procede com a conhecida Street execution of a vietcong prisoner, de Eddie Adams (1968), em que o plano secundário de fundo é reapresentado oferecendo um fragmento do que dificilmente se observa na imagem. Com esse procedimento, o artista acaba por negar a legibilidade do assunto, já que se trata de imagens completamente desfocadas. Apenas o título e a autoria escrita remetem às imagens originais. Portanto, a autoria do original vem como texto e não como imagem. Se, por um lado, pode-se pensar em citação em relação ao texto, na imagem isto já é questionável, pois ela se apresenta desconfigurada, dado o grau de desfocamento, o que a torna ilegível, além de acentuar a sensação de bidimensionalidade. Pode-se lembrar, pelos procedimentos de Dirnei, do filme Blow-up, de Antonioni, cujo personagem fotografa no parque e, após revelar, verifica que a figuração "explodiu", comprometendo a visibilidade do que fotografara.

Esta estratégia plástica de ampliar detalhes e dissolver a legibilidade figurativa da imagem foi empregada pelo artista pop Richard Hamilton, em obras como People (1968), na qual ampliou fotografias de pessoas, que se tornam vultos e manchas, em Praça Trafalgar (1965-67) e em Baía de Whitley (196566), muitas vezes tomadas de fotografias reproduzidas em cartões-postais. Como se sabe, determinadas obras da Pop Art trabalharam com princípios de apropriações fotográficas com técnicas de serialização, fragmentação e exposição de retículas, dentre outras.

A internet é outra fonte de imagens para construção de série fotográfica de Prates, a partir de um documento íntimo que é publicado em tempo real. Por meio de inscrição num site de relacionamentos em que as pessoas ficam expondo seus corpos ao vivo em situações de intimidade, o artista captou algumas imagens que originaram a série Júpiter, Netuno e Plutão (2014), ${ }^{15}$ o que resultou numa associação entre a fotografia e temas da pintura. Ao captar fotografias de nus desse site, o artista nomeia a série em referência ao afresco Júpiter, Netuno e Plutão (1599), de Michelangelo Caravaggio, por ser um afresco público com a evidência do nu. Porém, ao contrário da fama e dos poderes dos deuses, são figuras anônimas interessadas em expor seus corpos. Além das relações pictóricas e da associação entre o mundo da mitologia e o profano, as fotografias remetem à ideia de voyeurismo e questionam a privacidade, que é tornada pública.

Tendo realizado as primeiras fotografias, Dirnei diz ter percebido que algumas imagens remetiam ao tenebrismo da pintura caravaggesca, como uma das primeiras fotos, que denominou de Baco. Num segundo momento, já regulava a câmera para acentuar ainda mais a questão do tenebrismo: aumentava a
15. Essa série faz referência ao afresco Júpiter, Netuno e Plutão, pintado por Caravaggio no Gabinete de Alquimia do Casino dell'Aurora na Villa BoncompagniLudovisi Romana e encomendado pelo cardeal Francesco Maria del Monte. Obras dessa série de Prates participaram do $33^{\circ}$ Arte Pará (2014). 
Dossiê
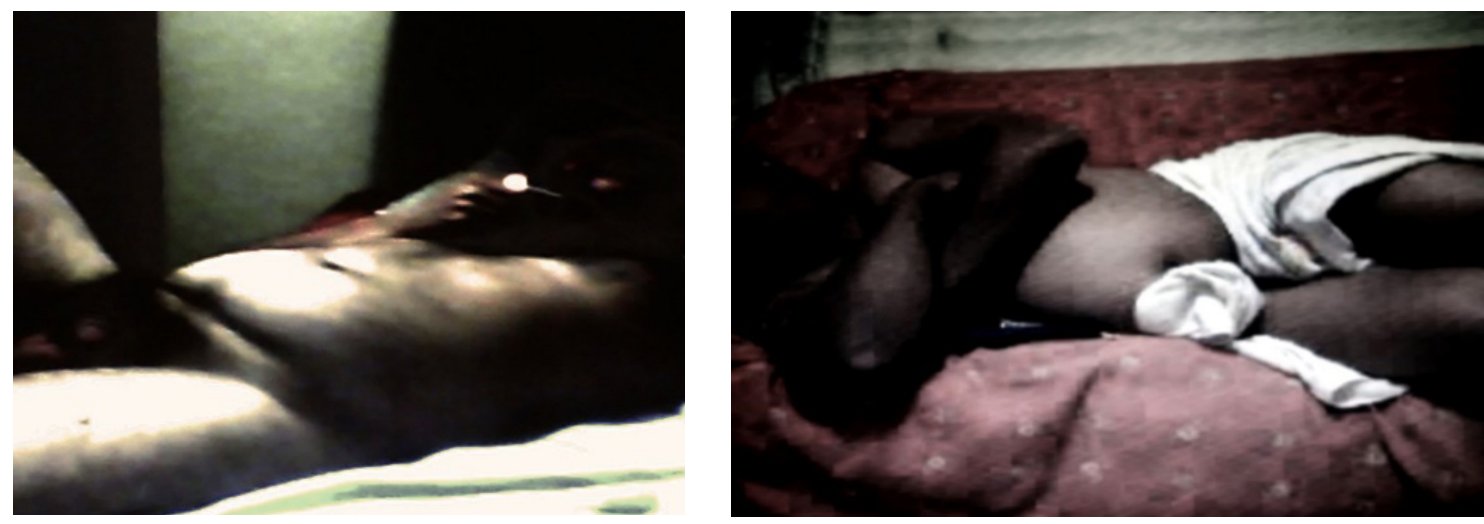

Figura 3. Dirnei Prates, Cupido dormindo (Série Júpiter, Netuno e Plutão), 2014, fotografia, $100 \times 150$ $\mathrm{cm}$, coleção do artista. Fonte: arquivo do artista.

Figura 4. Dirnei Prates, Repouso na fuga para o Egito (Série Júpiter, Netuno e Plutão), 2014, fotografia, 80 $x 120 \mathrm{~cm}$, coleção do artista. Fonte: arquivo do artista.
16. Entrevista à autora em 16 de janeiro de 2016. cor da tela para criar contraste e abria a profundidade de campo para ter as zonas escuras. Não lhe interessava a identidade fisionômica; por isso o corte das imagens transforma as figuras em acéfalas. Como eram corpos de "pessoas comuns, mais velhas, não esculturais", ele começou a pensar nos modelos de marginais do Caravaggio e no contraste entre luzes e sombras. Entretanto, ao contrário dos corpos caravaggescos, que apresentam sensualidade de musculatura escultural, os corpos fotográficos são desprovidos desses atributos. É esta discrepância que interessa ao artista, a de não ser uma referência literal.

Assim como nas escolhas dos títulos das fotografias de jornais de acidentes de trânsito, nessa série de nus, opta por obras que, por vezes, carregam um sentido trágico. Pelos cromatismos e contrastes de luzes, Prates começou a relacionar as imagens fotográficas captadas do site com os títulos de outras pinturas de Caravaggio: O Sacrifício de Isaac (1601/02), Decapitação de São João Batista (1608), David com a cabeça de Golias (1610) e A Deposição de Cristo (1602/03). Entretanto, embora alguns desses títulos remetam à ideia de violência, as imagens fotográficas não deixam transparecer nenhum conteúdo de agressividade. $O$ artista ressalta que não procurava uma literalidade com a obra do pintor, mas apenas algo que não tivesse caráter sacro nem pornográfico. ${ }^{1} 6$ Portanto, há uma descontinuidade entre a representação da imagem e a atribuição de títulos que instigam a violência.

Para outras de suas fotografias, busca uma relação de disposição espacial de corpos ou elementos de cena ou vestuário, como as referências às obras pictóricas Cupido dormindo (1608), que associa, na fotografia, a um corpo reclinado em repouso. A pintura O repouso durante a fuga para o Egito (c.1594/95), de Caravaggio, em que o anjo tem sua zona mediana envolvida num pano branco, o mesmo ocorre com o corpo de seu personagem fotográfico.

Esta série não deixa de ter um sentido irônico no que se refere a um dos grandes temas da história da pintura, ao contrapor imagens do mundo profano 
com aquelas sacras de títulos bíblicos da arte culta, e valores de liberdade em relação a práticas sexuais com os dogmas religiosos relativos ao uso do corpo, dentre outros.

A paisagem pictórica nomeia também alguns dos vídeos realizados por Dirnei como A noite estrelada, de Vincent Van Gogh (1889), e Impressão, nascer do Sol (1873), de Claude Monet, que compõem as partes, respectivamente, I e II do Filme caseiro (2014 e 2015). ${ }^{17}$ São fragmentos de momentos do cotidiano de passeios registrados entre 2004 e 2011 que, por meio da montagem, constroem uma narrativa quebrada cujo personagem aparece com aparências distintas, conforme a época do registro. Há uma distância iconográfica entre as obras pictóricas e os vídeos porque a ideia, segundo o artista, não era uma associação direta, mas a criação de ficções. A relação mais próxima é que, na primeira parte do vídeo, as cenas evocam uma atmosfera noturna nas cenas de paisagem, em preto e branco, com imagens difusas e jogos entre obscuridades e flashes de luzes, que conduzem a solidão do personagem em intervalos de som e quietude. Para o artista, a associação com A noite estrelada é pelo fato de o quadro ter sido pintado sem a observação direta da natureza, a partir da imaginação do pintor, por ocasião de sua internação no asilo. Se na primeira parte o vídeo termina ao findar da noite, a segunda começa ao amanhecer; daí a relação com a obra de Monet. Ambas as obras apresentam ruídos na imagem que interessam ao artista, devido à passagem de uma mídia em VHS para uma mídia digital, e tal fato proporciona certa perda de valor de realidade. Como nas séries fotográficas, não há uma literalidade entre as imagens e os títulos. Nos vídeos, os títulos de obras de arte têm objetivos mais poéticos que descritivos de significados por associações de temas, deixando ao espectador incógnitas abertas para relações semânticas entre as imagens em vídeos e pinturas.

A obra de Dirnei, portanto, não cessa de interrogar o conflito semântico entre as imagens e os títulos das obras, geralmente causando um estranhamento na expectativa do espectador. Do fotojornalismo à fotografia de arte e aos referenciais pictóricos, Dirnei Prates recicla imagens que reivindicam uma descontinuidade nos conteúdos de representação.

\section{IL - ATUALIZAÇÕES FOTOGRÁFICAS DE PAISAGENS PICTÓRICAS E JOGOS DE TRIVIALIZAÇÃO COM NUS}

Chegou-se a um momento em que o ateliê do artista pode ser o computador, sobretudo, para aqueles que trabalham com imagens de imagens. A correlação entre imagens disponíveis na internet com determinadas obras da História da Arte é uma das operações fotográficas realizadas pelo artista Felipe Cama, que se propõe a pensar como a imagem é produzida, distribuída e consumida. ${ }^{18}$
17. Esta segunda parte participou da mostra de filme livre no CCBB, Centro Cultural Banco do Brasil, no Rio de Janeiro, São Paulo e Brasília.

18. As imagens de todas as séries fotográficas de Felipe Cama se encontram no site do artista: www. felipecama.com.br. 
19. Uma série de um artista que revisita a tradição pictórica e que também utiliza o serviço de imagens do Google para a série Googlegramas é de Joan Fontcuberta. Ele reconfigura cada uma das pinturas, como a Última ceia, de Leonardo da Vinci, e A origem do mundo, de Gustave Courbet, por meio de dez mil reproduções fotográficas captadas da internet, que pela minúscula escala funcionam como pixels. Para a imagem de Jesus Cristo da Última ceia, ele escreveu "paz" em 86 idiomas, com o que construiu a composição como uma espécie de mosaico pouco decifrável pela quantidade. Com essa operação, 0 artista refaz uma imagem do passado da pintura com a tecnologia do contemporâneo. Esses trabalhos não deixam de ser um comentário sobre a questão da reprodutibilidade técnica da imagem, que traz mais interesse do que o próprio real. Numa conferência que realizou em Paris em de fevereiro de 2012, 0 artista projetou um vídeo que mostrava uma mulher caminhando em meio à multidão do Museu do Louvre e apontando indiscriminadamente 0 celular para obter fotografias das obras de arte, não vendo sequer 0 que estava fotografando; apresentou também uma fotografia de uma visita do Papa, onde havia centenas de câmeras fotográficas apontadas para ele. Não havia um interesse pelo real, mas pela imagem do real.
É no gigante e instantâneo portal de informações do Google ${ }^{19}$ que o artista acessa imagens para reconfigurá-las como produções fotográficas que, por meio de modos operatórios, criam a evidência da linguagem digital, pois, como se sabe, os diálogos dos artistas com o cálculo numérico cada vez mais se acentuam na arte contemporânea. Em sites da Internet, o artista seleciona reproduções de pinturas da tradição moderna e clássica para refigurá-las com uma linguagem numerizada. Se uma fotografia de base química podia explorar o grão da matéria como superfície fotográfica, agora Cama usa os efeitos planares de constituição de uma imagem numérica, de forma a torná-la pixelizada. Assim, anula toda a superfície dos gestos de pinceladas de imagens icônicas da história da pintura. Esta operação padroniza as imagens e coloca em crise a identificação do gesto autoral dos autores das pinturas. Para compor a sua linguagem numérica, o artista escolheu reproduções pictóricas tradicionais da pintura: o nu e a paisagem.

$\mathrm{O}$ nu, longe de ser um fator marginal na história da fotografia, teve um grande interesse tanto por parte de artistas quanto de um público anônimo. A grande produção deste gênero visava a atender ao menos duas frentes. Os artistas requisitavam fotografias para suas composições plásticas, em poses sensuais ou meramente de corpos reclinados em poltronas, camas, em meio a cortinados, como nas pinturas de Gustave Courbet e Eugène Delacroix, realizadas a partir de fotografias de Vallou Villeneuve. Outra procura era pelo nu obsceno, sobretudo, nas fotografias estereoscópicas, portanto, em 3D, cujas poses revelavam claramente as zonas sexuais com a finalidade de atender uma clientela masculina, como mostram as fotografias produzidas por Auguste Belloc. A fotografia foi, portanto, desde o seu início, provedora de imagens que alimentaram o imaginário do nu.

Se no século XIX essa função competia à fotografia impressa, em tempos de internet, o acesso ficou ainda mais instantâneo e gratuito. Na rede digital, Felipe Cama encontrou muitas das imagens de nus que passou a utilizar em suas composições associadas aos nus da História da Arte. Dada a quantidade de imagens que circulam na internet, Felipe pratica o que Régis Durand aponta como característica do artista contemporâneo, que é a administração no manejo e a reciclagem de imagens, provocando novas associações e ressignificações de imagens de imagens, utilizando misturas de referências, fazendo jogos com a história das imagens por meio da citação de referências pictóricas em suas fotografias.

Na série Nus after (2004-2010), Felipe Cama recria digitalmente obras pictóricas de Monet, Gauguin, Modigliani, Matisse e Van Gogh com um procedimento de pixelização. Como são imagens muito conhecidas, como em $\mathrm{Nu}$ (after Gauguin) e Nu (after Matisse), mesmo tendo aplicado esse método de 


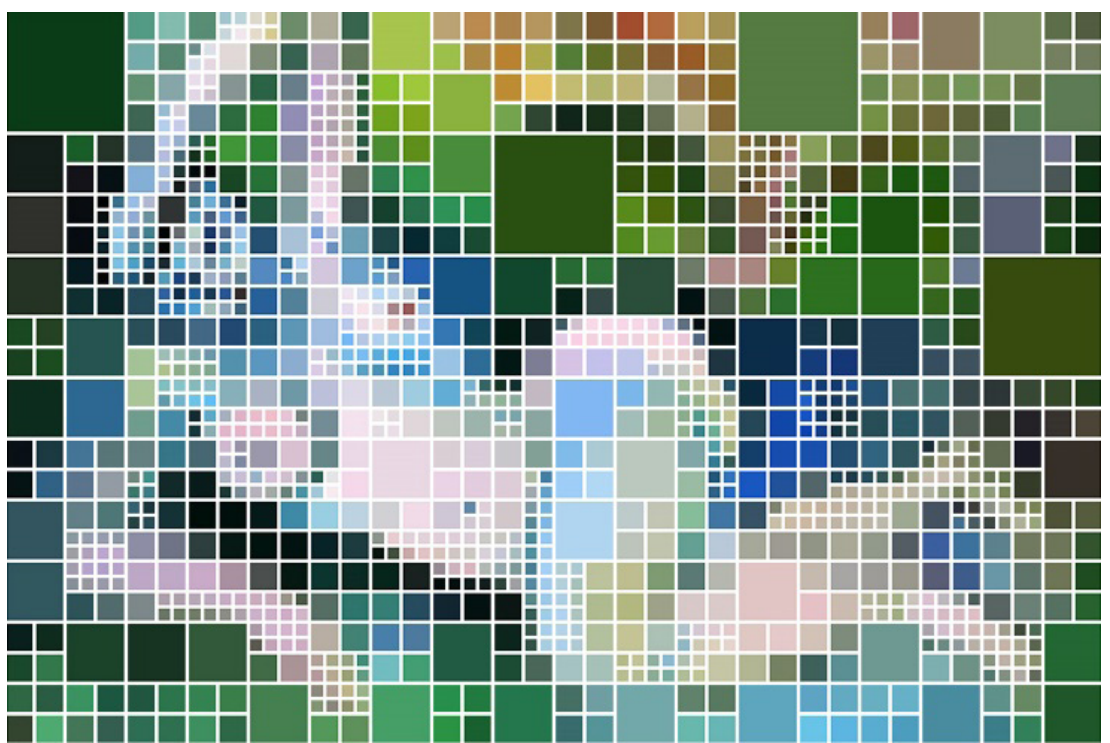

Figura 5. Felipe Cama, Nu (After Matisse) \#1, 2004-2005, fotografia, impressão digital, 83 x $124 \mathrm{~cm}$. Fonte: arquivo do artista.

Figuras 6 e 7. Felipe Cama, Karine x Freud, 2006, fotografia, impressão lenticular, $69 \times 80 \mathrm{~cm}$, duas vistas da obra, lâminas A e B. Fonte: arquivo do artista.
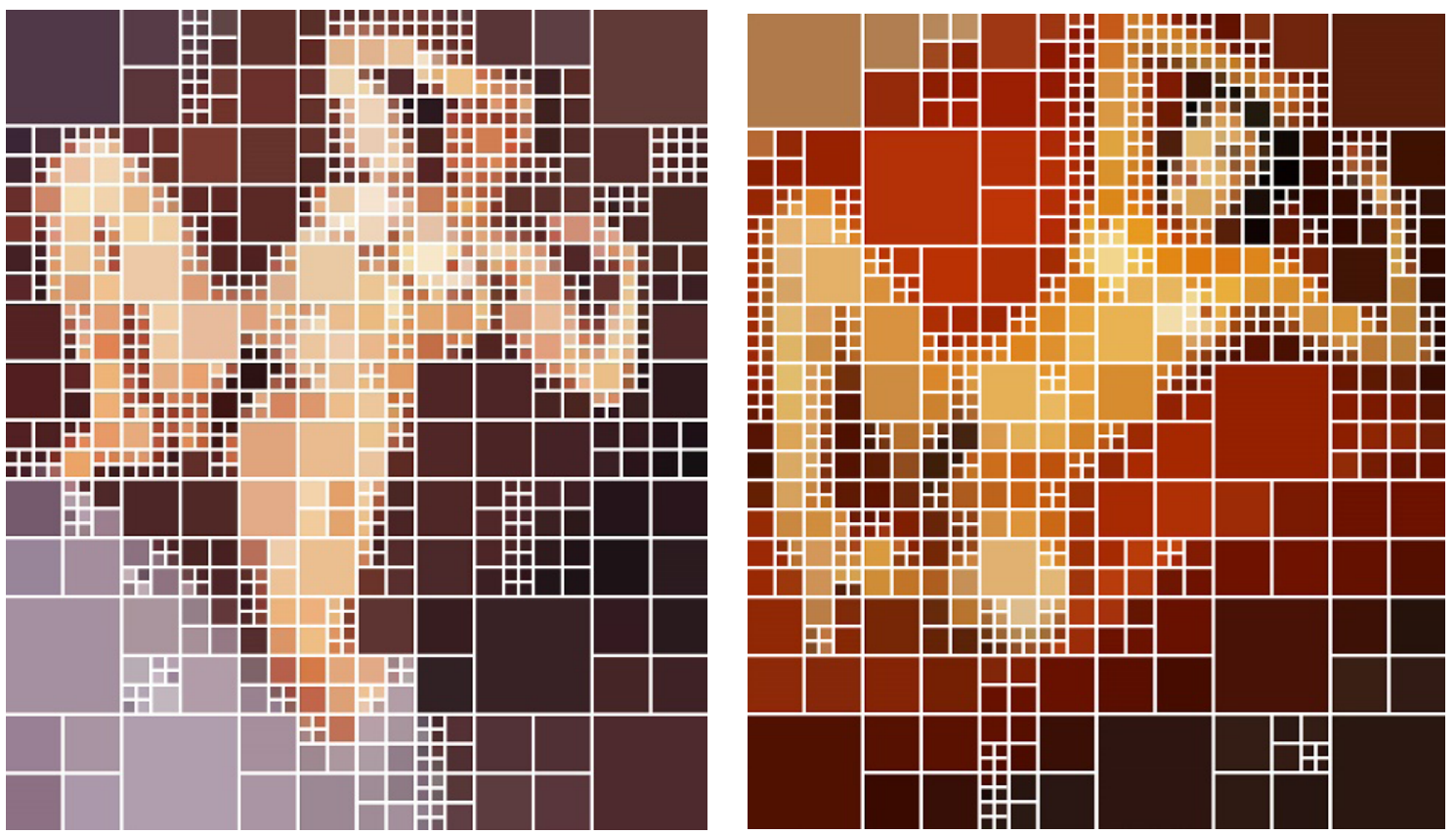
20. A impressão lenticular exige a presença do espectador na frente da obra para ser percebida, pois filetes verticais de cada imagem são interpostos e recebem uma lente plástica cujo efeito é tal que vemos uma ou outra imagem à medida que nos movemos ante a obra, recuperando a dimensão irredutível da experiência da fruição in loco que a arte demanda. Ver: Silvia Barreto, After Post, em <http://www. felipecama.com/after-post-texto>.

21. Os títulos fazem referência à obra original: Dois nus parecidos, um after Courbet (2005), Quatro nus parecidos, dois after Picasso (2005-2006), Dois nus parecidos, um after Modigliani (2005), $\mathrm{Nu}$ (after Matisse) \#1 (2004-2005), $\mathrm{Nu}$ (after Matisse)\#2 (2010) e Nu (after Van Gogh) (2004-2005), dentre outros. composição, ainda é possível reconhecê-las como sendo desses artistas, pelos formatos e posições dos corpos. Mas, ao causar o desaparecimento da pincelada gestual que diferencia um artista modernista de outro, a imagem acaba por ser padronizada enquanto superfície planar visual. 0 mesmo tratamento, embora variando seus cromatismos, é atribuído a todas as suas obras fotográficas desta série que referenciam a pintura. Tal procedimento formal pode apresentar um teor irônico em relação às culturas que, por força das circunstâncias em relação às distâncias de onde se encontram as obras originais, precisam conhecê-las por reprodução, sem que possam ter o contato visual diretamente com as cores e texturas das pinceladas. $E$ isto leva a pensar de que forma ocorre a apreciação de obras de arte.

$\mathrm{Na}$ outra série, denominada de Nus parecidos (2005-2009), o artista busca, por meio de impressão lenticular, ${ }^{20}$ uma associação entre dois nus femininos semelhantes, especialmente nas poses, a partir de reproduções de pinturas a óleo de nus criadas por Picasso, Modigliani ou Van Gogh, que são associados a nus pornográficos anônimos, retirados de sites ou de imagens que o artista recebeu por e-mail. As fotografias Sabrina x Modigliani (2006), Karine $x$ Freud (2006) e Pâmela x Picasso (2007) carregam os nomes adotados pelas mulheres fotografadas e os nomes dos referidos artistas, de forma a confrontar os diferentes contextos e finalidades das imagens que se encontram na rede digital. Apesar de o nu ter sido, como se sabe, um gênero muito representado na história da pintura, não se pode deixar de pensar nos jogos de trivialização das imagens ao justaporem-se reproduções de origem pornográfica que circulam em sites com essa finalidade a imagens de obras que circulam nos museus, nas casas dos colecionadores, no mundo da arte. Entretanto, enquanto imagens reprodutíveis, ambas circulam em ambientes virtuais, portanto um consumo que ocorre na mesma plataforma virtual.

Embora ainda seja perceptível nas séries fotográficas uma pequena noção de volume pelas diferenças de tonalidades em partes dos corpos, a malha geométrica que explora diferentes tamanhos de mosaicos e as superfícies cromáticas planares acabam impondo bidimensionalidades iconográficas às figuras. As planaridades fotográficas destroem as individualidades de pinceladas modernistas ou criam enfrentamento com os códigos tradicionais de mimetismo do tratamento do nu clássico pictural. Assim, o grau de abstração é maior que os códigos figurativos, especialmente nos espaços que circundam as figuras. 0 grande formato das imagens, como um mural, contribui para acentuar a planaridade dos corpos e a visibilidade de cores. Isto solicita ao espectador um distanciamento para reconfigurar a imagem representada. ${ }^{21}$ Dessa forma, o artista tensiona ao máximo a figuração das imagens pictóricas apropriadas, assim como a própria natureza figurativa da fotografia. 


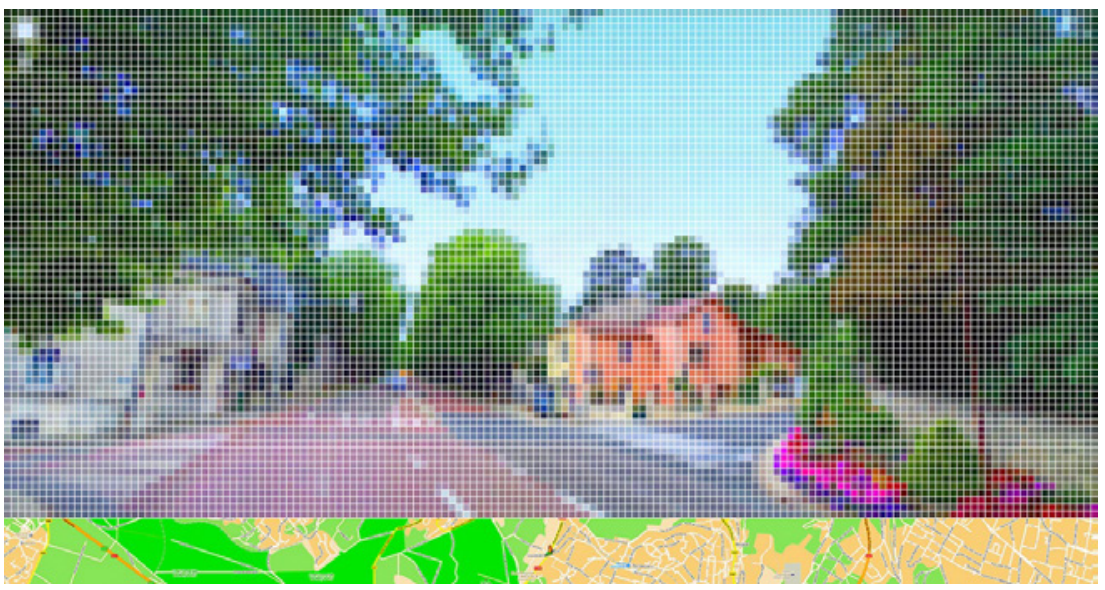

Se, a partir do século XIX, com as excursões daguerreotipianas, a fotografia passou a alimentar o imaginário das pessoas com fotos de paisagens, hoje, com Google Street View, ${ }^{22}$ o acesso a imagens de paisagens ocorre de forma muito mais rápida, instantânea e sem custos. 0 título da série de Paisagens Street View (2011), de Felipe Cama, é indicativo de todo o seu processo de trabalho. A tecnologia está a serviço do projeto do artista, que nela encontra a possibilidade de realizar reflexões sobre a ideia de memória e de tempo. Após selecionar obras de artistas de seu interesse - Frans Post, Vermeer, Cézanne, El Greco, Turner, Ruisdael, Corot, Constable, Delacroix e Sisley -, Felipe utiliza os títulos das pinturas de paisagens realizadas por esses artistas para, por meio do aplicativo Google Street View, encontrar imagens atuais dos mesmos locais que os pintores registraram em suas pinturas. As fotografias desses lugares, na maioria das vezes, apresentam mais diferenças que semelhanças com os locais registrados nas obras pictóricas, devido às transformações físicas ocorridas nos locais pela passagem do tempo, ao ângulo fotografado pelo aplicativo, que, obviamente, não é o mesmo do enquadramento concebido pelo pintor, como se verifica em After Cézanne, Montain Saint Victoire (Street View) (2011). Esse descompasso de distanciamento entre as imagens é ainda mais visível em paisagens com rios e árvores, como em After Delacroix L'Etang de Beauregard dans La Commune Le Louroux (Street view) (2011) e em After Constabel View on the Stour near Dedham (Street view) (2011). Abaixo das imagens, consta o mapa do lugar. Na verdade, os títulos dados às fotografias é que denunciam os ancestrais picturais aos quais fazem referências, como na fotografia After Sisley (Early Snow at Louvenciennes) (Street View) (2011).

As pinturas dos locais pelos artistas servem, então, de pretexto para a busca dos mesmos lugares. Não se pode resgatar o gesto do pintor, nem essa é a intenção do artista, porque o resultado é o discurso plástico de imagem
Figura 8. Felipe Cama, After Sisley "Early Snow at Louveciennes" (Street View), 2011, impressão em metacrilato, $63 \times 120 \mathrm{~cm}$. Fonte: arquivo do artista.
22. A qualidade da tecnologia fotográfica empregada para a localização de lugares alcança cada vez mais precisão; em alguns casos, pode-se ver com grande detalhamento a imagem da rua, o número do edifício e, conforme 0 ângulo fotografado, até mesmo dentro de uma residência. Associar os recursos de tecnologia do contemporâneo com a tradição pictórica é um procedimento comum nas práticas fotográficas da atualidade, como fez Joan Fontcuberta, na série Ortogénesi, gerando, por meio de um software, imagens a partir de obras de arte de Munch, Millet, Hokusai,Turner e Derain, dentre outras. 
23. Frans Post esteve no Brasil entre 1634 e 1642. numerizada com a presença de uma malha branca que se sobrepõe às iconografias de suas paisagens fotográficas. A apresentação da paisagem quadriculada por essa grade de linhas pode evocar o princípio didático da tela geometrizada como forma de capturar uma paisagem pictórica clássica ou como o recurso do desenho para uma ampliação de imagem, mas pode ainda lembrar a configuração visual de imagens digitais quando ampliadas. A presença dessa grade digital uniformiza todas as fotografias das séries, criando um padrão sobre a representação. É esse padrão que acentua certa bidimensionalidade da imagem, como faz também com as representações de nus.

Com o foco nesse mesmo regime de imagens e na fotografia predatória da internet, o artista já havia criado uma série anterior, denominada After Post (2010), na qual mesclou imagens de pinturas de Frans Post ${ }^{23}$ com fotografias de regiões do nordeste brasileiro realizadas por amadores e encontradas nos arquivos do Google. Ele as denomina, por exemplo, Pernambuco (after Post), Olinda (after Post), Natal (after Post), João Pessoa (after Post). 0 artista não esteve nos lugares registrados por Post, mas conhece-os por meio de imagens fotográficas, de forma que a imagem é a mediadora da percepção do artista com o real. A visão daqueles lugares ocorre por intermédio do olhar do outro.

Nessas fotografias, o artista também sobrepõe uma malha, que, além de deixar evidente a natureza digital de constituição da imagem por pixels, ameniza a perspectiva, os volumes e as texturas da paisagem, formando um contraponto com a ideia de manualidade e com o detalhismo iconográfico das pinturas de Post. 0 achatamento dos volumes do trabalho original acaba por interrogar sobre a natureza de verossimilhança historicamente atribuída à fotografia. 0 artista parece querer extrair das pinturas de Post e das fotografias apropriadas somente a constituição cromática e suas platitudes.

Atualizar fotograficamente paisagens pictóricas que foram produzidas em diferentes épocas e justapor nus criados com finalidades e contextos diversos são formas de comentar sobre o consumo de imagens no mundo contemporâneo, pois, embora seus propósitos e regimes de produção tenham sido diferentes, todas podem ser visualizadas na mesma plataforma do mundo digital. Isto faz pensar no quanto a percepção do real tem sido mediada pelos códigos da imagem.

Antinomias e convergências nos empréstimos de imagens, títulos de obras e nomes de artistas da tradição pictórica são fontes norteadoras para as práticas fotográficas de Dirnei Prates e Felipe Cama. Esses artistas provocam compartilhamentos entre imagens retiradas de diferentes contextos, "imagens que não são arte", referenciando Elkins, que passam a relacionar-se numa mesma obra, como os nus pornográficos captados na mídia digital por Prates e Cama, que convivem com referências ou reproduções da história da pintura. Frente à 
avalanche de imagens do mundo contemporâneo, Dirnei e Felipe propõem o remanejo e a reciclagem fotográfica, atribuindo ressignificações e atualizações em imagens de paisagens, tanto do presente quanto do passado. Nesses artistas, o caráter narrativo textual dos títulos dos trabalhos parece ser indissociável das imagens. Assim, as tecnologias contemporâneas multimídias e os mananciais da tradição pictórica serviram de arcabouço para processos fundacionais de suas práticas artísticas fotográficas.

\section{REFERÊNCIAS}

BARRETO, Silvia. After Post. In: FELIPE Cama: txts. Disponível em: <http://www.felipecama.com/after-post-texto>. Acesso em 18 de fevereiro de 2016.

DURAND, Régis. La Experiencia Fotográfica. Ciudad de México: Ediciones Ve, 2012.

ELKINS, James. História da arte e imagens que não são arte. Porto Arte, Porto Alegre, v. 18, n. 30, maio 2011.

MOREL, Gäel (Org.). Photojournalisme et Art Contemporain.

Paris: Éditions des Archives Contemporaines, 2008.

PICAUDÉ, Valérie; ARBAÏZAR, Philippe (Org.). La confusión de los géneros en fotografía. Barcelona: Gustavo Gili, 2004. PRATES, Dirnei. Entrevista à autora em 15 de janeiro de 2016.

\section{Niura Legramante Ribeiro}

Mestra em Artes pela Escola de Comunicação e Artes da Universidade de São Paulo, ECA/USP, e Doutora em Artes pelo Programa de Pós-Graduação em Artes Visuais da Universidade Federal do Rio Grande do Sul, PPGAV/UFRGS, com a tese Entre a lente e o pincel: interfaces de linguagens. Professora e pesquisadora do Departamento de Artes Visuais e do PPGAV/UFRGS. Realiza pesquisas, curadorias e publicações sobre a fotografia e suas reverberações com a pintura, a gravura e o desenho. 
